\title{
Health Promotion to Patients with Pelvic Floor Dysfunction: An Integrative Review
}

\author{
Karine C. Bezerra, José A. Vasconcelos Neto, Leonardo R. P. S. Bezerra, Sara A. L. Karbage, \\ Isabella P. R. Frota, Camila T. M. Vasconcelos, Mônica O. B. Oriá \\ Department of Nursing, Federal University of Ceará, Fortaleza, Brazil \\ Email: karineufc@gmail.com
}

Received 29 January 2015; accepted 7 March 2015; published 12 March 2015

Copyright @ 2015 by authors and Scientific Research Publishing Inc.

This work is licensed under the Creative Commons Attribution International License (CC BY). http://creativecommons.org/licenses/by/4.0/

c) (i) Open Access

\begin{abstract}
Introduction and Hypothesis: The Pelvic Floor Dysfunction (PFD) is a common gynecological condition that causes significant morbidity in the affected population, increasing clinical and financial challenge for the Public Health Services. Methods: This study aimed to review the available evidence and interventions to promote the health of women with PFD. We used the following databases to select papers for this review: Scopus, PubMed, CINAHL, LILACS and Cochrane. The sample consists of seven articles, with evidence levels 1 and 2 . Results: The results of the articles point out to a greater number of activities related to the management of Urinary Incontinence (UI) behavioral support to the patient and physical therapy of the pelvic floor muscles. They were both beneficial to UI prevention and treatment. Conclusions: The physical therapy approach, when associated with cognitive and behavioral strategies, leverages UI outcomes in patients.
\end{abstract}

\section{Keywords}

Evidence-Based Practice, Health Promotion, Intervention Studies, Pelvic Organ Prolapse, Urinary Incontinence

\section{Introduction}

Pelvic Floor Dysfunction (PFD) affects millions of women around the world, leading many to cope with a poor health condition and lack of specialized treatment [1] [2]. An increased prevalence of predisposing factors, such as obesity and aging, is contributing to the rise of PFD with escalating hospital and resource costs.

It is expected that future referrals for PFD-related health care will increase $50 \%$ over the next 30 years, overloading the current health system [3]. Concerned about this scenario, many professionals are seeking strategies to prevent PFD and to reduce the disease burden, contributing to improve the quality of life through the aid of 
scientific evidence strategies [4].

Thus, the aim of this integrative review is to summarize the current literature available covering PFD successful interventions to health promotion of these women [5]. Results obtained from this review may assist health professional to deal with this condition and to guide their clinical practices towards disease amelioration.

\section{Method}

A literature search was performed to answer the clinical question, "What are the most effective interventions to prevent PFD and to promote the health of women with PFD?” Five databases were examined: CINAHL MEDLINE via PubMed, Cochrane Collaboration and Library, Scopus and LILACS (Latin American and Caribbean Literature on Health Sciences), using the following keywords in different sets of combinations: Pelvic organ prolapse; urinary incontinence; health promotion.

Articles were included if they were written in comprehensive English, Spanish and Portuguese, reporting interventional strategies to improve health in women afflicted with PFD.

Seven articles were found pertinent to the clinical question (Figure 1) and were appraised for quality and methodological rigor using standardized assessment tools to verify evidence level [6], to evaluate the PFD outcomes [1] and to categorize the type of intervention in behavioral, cognitive or social [7]. Behavioral interventions are those that propose stimuli associated with treatment adherence (e.g. reminders). Cognitive interventions are those that provide new information, educate women about the types of treatment and clarify possible misconceptions. Social interventions include counselors (people in the community trained to provide information) or health professionals to increase adherence to treatment [7].

The interventions were categorized in: Primary strategy-interventions with the aim of removing the PFD causes, when possible (example: behavioral support and counseling to women after menopause); Secondary strategiesthat alleviate or prevent the worsening of a previously existing PFD; and Tertiary strategies-seek to support women who handle permanent devices to alleviate PFD; or Curative strategies, in the case of surgical procedures [8].



Figure 1. Study search and selection. 


\section{Results}

Regarding the databases, three articles were identified in PubMed, two in Scopus and two in Cochrane. Regarding the methodological design, the articles were classified as: systematic review $(n=2)$ and randomized controlled trials $(n=5)$. It is noteworthy that almost all the reviewed studies dealt with the prevention and management of the Urinary Incontinence (UI) and only one approached the Pelvic Organ Prolapse (POP). Thirty one types of intervention were identified, alone or combined with others. Among these interventions, five were considered primary intervention, twenty-four were considered secondary and two were identified as tertiary intervention (Table 1).

To evaluate the intervention outcomes, different measures were identified (Table 2) enrolling complaints reported by the patient and the impact on quality of life assessed by scales previously validated [12]-[15]. The interventions described in these studies were targeted from prevention of PFD to its healing and are described in three levels.

\subsection{Primary Intervention}

Primary interventions found in this review enrolled postpartum women [14], older [9] [12] [13], and postmenopausal women [9]. In all studies, subjects had already shown signs and symptoms of some type of PFD (UI or POP), however, without knowledge or diagnosis about this condition.

Table 1. Characteristics of studies.

\begin{tabular}{|c|c|c|}
\hline Studies & $\mathrm{N}$ & Reference \\
\hline \multicolumn{3}{|l|}{ Evidence } \\
\hline Level 1 & 02 & [9], [10] \\
\hline Level 2 & 05 & {$[11]-[15]$} \\
\hline \multicolumn{3}{|l|}{ Type of PFD } \\
\hline Urinary Incontinence & 06 & {$[10]-[15]$} \\
\hline Pelvic Organ Prolapse & 01 & [9] \\
\hline \multicolumn{3}{|l|}{ Classification of Intervention $\left(n=31^{*}\right)$} \\
\hline \multicolumn{3}{|l|}{ Outcomes } \\
\hline Primary & 05 & [9], [12]-[14] \\
\hline Secondary & 24 & [9]-[13], [15] \\
\hline Tertiary & 2 & [10] \\
\hline \multicolumn{3}{|l|}{ Strategies Used } \\
\hline Behavioral & 13 & {$[10]-[14]$} \\
\hline Cognitive & 07 & [11]-[15] \\
\hline Social & 11 & [9], [10] \\
\hline \multicolumn{3}{|l|}{ Approach } \\
\hline Behavioral Therapy & 06 & [12]-[15] \\
\hline PFDT & 15 & {$[10]-[15]$} \\
\hline Bladder Training & 01 & [10] \\
\hline Medicine & 01 & {$[10]$} \\
\hline Hormony Therapy & 04 & [9] \\
\hline Mechanical Supports (Pessaries) & 01 & [10] \\
\hline Surgery & 01 & {$[10]$} \\
\hline Physical Training with Vaginal Cones & 01 & {$[10]$} \\
\hline Electric and/or Magnetic Stimulation & 01 & [10] \\
\hline
\end{tabular}

* Some studies enrolled more than one intervention. 
Table 2. Categorization of studies according to the evaluation of interventions outcomes.

\begin{tabular}{|c|c|c|}
\hline Study & $\mathrm{N}$ & Reference \\
\hline \multicolumn{3}{|l|}{ Assessment Measures } \\
\hline -Observations of the Patients' Symptoms & 5 & [9]-[12], [15] \\
\hline -Quantification of Symptoms & 7 & [9]-[15] \\
\hline -Clinical Observations (Anatomical and Functional) & 3 & [9]-[11] \\
\hline -Quality of Life & 5 & [9], [10], [13]-[15] \\
\hline -Socioeconomic Implications & 2 & [9], [15] \\
\hline \multicolumn{3}{|l|}{ Measurements Instruments } \\
\hline \multicolumn{3}{|l|}{ Quantification of Symptoms } \\
\hline -International Consultation on Incontinence Questionnaire, ICIQ & 1 & [12] \\
\hline -Severity Index in Female Urinary Incontinence & 1 & [14] \\
\hline -Questionnaries Not Validated & 2 & {$[11],[13]$} \\
\hline -Voiding Diary & 1 & [15] \\
\hline -Self-Report & 2 & [9], [10] \\
\hline \multicolumn{3}{|l|}{ Specific Quality of Life } \\
\hline -Incontinence Quality of Life Instrument, I-QOL & 2 & [10], [13] \\
\hline -Incontinence Impact Questionnaire, IIQ-7 & 2 & [10], [14] \\
\hline -Incontinence Impact on Life Questionnaire Adapted & 1 & [15] \\
\hline -Urogenital Distress Inventory, UDI-6 & 2 & [10], [14] \\
\hline -Prolapse Quality of Life Questionnaire, PQol & 1 & [9] \\
\hline \multicolumn{3}{|l|}{ General Quality of Life } \\
\hline -Self-Report Questionnaires, SF-12 & 1 & {$[13]$} \\
\hline -Quality of Life Scale, QoLS-N & 1 & {$[10]$} \\
\hline \multicolumn{3}{|l|}{ Socioeconomic Implications } \\
\hline -Specific Questions Aboute Conomic Costs of disease & 2 & [9], [10] \\
\hline \multicolumn{3}{|l|}{ Observations of the Patients' Symptoms } \\
\hline -Patient’s Global Impression of Improvement, PGI-I & 1 & [12] \\
\hline -Questionnaries Not Validated & 1 & [11] \\
\hline -Self-Report & 3 & [9], [10], [15] \\
\hline \multicolumn{3}{|l|}{ Clinical Observations } \\
\hline -Pelvic Organ Prolapse Quantification System, POP-Q & 1 & {$[9]$} \\
\hline -Padtest & 2 & [9], [11] \\
\hline -Physical Examination & 2 & [9], [10] \\
\hline
\end{tabular}

Behavioral therapy and the Pelvic Floor Muscle Training (PFMT) were the main approaches used in the prevention of UI [10]-[15]. Only one study evaluated the use of hormones in preventing POP [9]. The intervention strategies were varied. Cognitive and behavioral strategies prevailed. They were used individually or in association, with duration variable from four days to six months. They used tools like workshop [12], training with specialists [13] [14], booklet [14], slides [12], flyers [13] [14], and reminder to realize PFMT [14]. The use of different strategies together proved to be effective in preventing PFD [14].

Interventions using reminders (posters or phone calls) had great impact in regards to adherence to behavioral therapy and the PFMT. They improved the quality of the exercises (control group: 57.6\%, intervention group: 
83.9\%), or increased the number of exercises performed daily. There was a variation in the rate of daily exercises: 0 exercises before the intervention to 3 times a week or more after intervention $(p=0.001)$ [14]. These interventions are based on the assumption that people only need a stimulus (reminder) to practice proper conduct. For women, this stimulus can be done through phone calls or reminder posters to encourage the realization of exercises [14] and activities based on behavioral therapy [12].

Overall, the results were encouraging. They showed prevention of UI with use of PFMT or behavioral therapy (range 66\% to 69\%) [12] [14]. They observed better self-knowledge with self-control ability of continence [12], and adhesion to the practice of pelvic floor exercises at adequate levels $(80 \%$ to $88 \%, p=0.001)$ [14].

\subsection{Secondary Intervention}

The main goal of these interventions was to use approaches for improving the signs and symptoms of PFD. Aiming to verify the effectiveness of using a website (Group 1) and an educational booklet (Group 2), a study showed significant decrease in episodes of incontinence after receiving the intervention with the above educational technologies compared to individuals in the control group (no intervention) [15]. They used the assumptions of behavioral therapy for improving UI symptoms and quality of life. There was a significant change in reported mean of UI episodes among subjects over time (Group 1 ranged from 7 to 2.8, Group 2 ranged from 6 to 2.9, control group: ranged from 5 to 4.3 ; $\mathrm{p}=0.001$ ). Furthermore, the mean rate of decrease in UI episodes was significantly different between Groups 1,2 and control $(p=0.02)$ [15].

A systematic review compared PFMT alone and in combination with other active educational treatments for UI. Some women reported cure or improvement of incontinence compared the PFMT associated with vaginal cones $(93 \%)$ and the isolated use of vaginal cones (75\%), showing significant correlation (RR 1:27, 95\% CI: $0.94-1.71)[10]$.

With respect to specific quality of life, in the same study, no statistically significant differences was seen between women with Stress Urinary Incontinence (SUI), Urge Urinary Incontinence (UUI) or Mixed Urinary Incontinence (MUI) who received PFMT added to bladder training and those who received bladder training (including scheduled voiding regimen). This study has measured the quality of life using the Incontinence Impact Questionnaire-Revised scale (mean difference -5.90 , 95\% CI: -35.53 to 23.73) and Urogenital Distress Inventory (mean difference $18.90,95 \%$ CI: -37.92 to 0.12 ) [10].

Another study evaluated the effect of a program (Continence Efficacy Intervention Program) in women with SUI designed to improve adherence of women to perform the PFMT. The program was composed of cognitive and behavioral strategies using pamphlet, a loaned audiovisual tape, calendar, schedule guideline and phone call for counseling, encouraging, teaching accurate performance, assessing, self-care methods and confirmation of methods [11]. The results found that almost all individuals in the intervention group stated that the phone support was important in encouraging the PFMT. The use of the pamphlet and the video was helpful to initial learning, but once they learned how to do the exercise, there was no need for further use. Other participants said that the calendar was useful because it told them how many times they practiced exercise and how many times they experienced urinary loss every day [11].

In the same study, the subjective assessment of symptoms before and after the intervention showed different scores, with improved scores after the intervention $(\mathrm{p}<0.05)$ [11]. It was found that most studies using educational programs addressing behavioral therapy and the PFMT to reduce urinary symptoms, employed theories that helped the expected results. The main theories were self-efficacy theory [11], and self-management theory [12]. It is noteworthy, interdisciplinary participation of health professionals in the programs for the promotion of continence including nurses, physician and physiotherapists [10] [11] [13].

\subsection{Tertiary Intervention}

Only one study [10] reported tertiary interventions. The main objective of the review was to compare the effects of PFMT combined with other active treatments (pessaries, vaginal cones, electrical stimulation, bladder training, behavioral therapy and drug therapy) with to the same active therapy alone in treating women with UI.

The sample consisted of 446 women with symptoms of UI, divided into three groups: Group 1: use of continence pessary alone $(n=149)$, Group 2: behavioral therapy plus PFMT $(n=146)$ and Group 3: use of pessary continence in combination with the PFMT $(n=150)$. Continence pessaries were inserted successfully by doctors or nurses in the clinic. They were performed up to three follow-up visits with two week intervals until the pa- 
tient self properly insert the device. Improvement of symptoms was assessed by the patient global impression of improvement (PGI-I), the patient self-report and by voiding diary. The success was defining as a reduction of $75 \%$ (or more) in the frequency of incontinence episodes weekly. The specific quality of life was also evaluated using the scale Urogenital Distress Inventory-stress incontinence sub-scale successfully defined as the proportion of subjects with no symptoms of urinary urgency and effort. In this investigation the improvement of symptoms was observed only by voiding diary.

The results showed improvement and cure rates of self-reported incontinence among women who received PFMT added to continence pessaries and those who were treated only with pessaries in time intervals of six months (80/132 against 69/110, RR 0.97, 95\% CI: 0.79 to 1.18) and 12 months (51/96 against 52/111, RR 0.88, 95\% CI: 0.67 to 1.16) after the treatment onset [10]. However, despite the improvement of self-reported incontinence in women using pessaries in combination with PFMT, the results were not sufficient to detect any significant statistical power difference in the primary outcomes of interest of the above review [10].

\section{Discussion}

This review showed that many barriers in relation to patients' adherence to the PFD treatments can be overcome with well-designed interventions. The selection of interventions to be applied must take into account the specific characteristics of each population or health service. An example of this is the evidence that older women benefit more from behavioral interventions with workshops [11], while women of reproductive age prefer cognitive interventions using reminders [14].

Another important aspect to be considered in the implementation of interventions is the location or environment. It is important to understand all areas of service delivery as potential health promoting environments, for example, nursing homes. It has the valuable opportunity to discuss the symptoms related to PFD, especially the demographic profile of this area. It is known that the PFD can be present in women with varying ages, but advancing age is one of the most significant risk factors to the manifestation of POP or UI. Accordingly, you should instigate activities to promote health of the pelvic floor in these spaces, and they can be cognitive, social or behavioral.

The presence of statistically significant relationships between activities to promote continence and improvement of symptoms in elderly community [11] subsidizes the hypothesis that the intervention in their local housing may improve adherence and continuity of PFMT. This suggests that health professionals were receptive to the idea of discussing the promotion of continence in strategic areas, where there may be people with high risk factors for this condition.

The other convenient space is the hospital. This can be evidenced through the implementation of a program for prevention of incontinence in a university hospital to women with UI without prolapse in postpartum period [14]. The most direct implication of this study was the recommendation of PFMT to prevent PFD just in immediate postpartum period. Additionally, ask questions about this condition, through cognitive and behavioral strategies, exploring varying capabilities (telephone reminder, educational manual, brochures and posters adhesives).

The importance of evaluating the quality of life as an interventional result was clearly evidenced in this review. Most studies measured this outcome, confirming the importance of this measure to determine the effectiveness of the results, either through specific [9] [10] [13]-[15] or general questionnaires [10] [13].

Although the impact on quality of life, relatively few incontinent women seeking treatment for the problem with the demand rate of $6 \%$ to $14 \%$ [16]-[18]. Studies reveal that $56 \%$ of women with UI do not seek professional help; in $71 \%$ of cases because they consider the problem as something normal and $9.7 \%$ because they believe that it has no solution [19].

In this context, knowledge about their condition is very important for an effective result. It is important also in seeking and treatment adherence. Among the studies evaluated in this review, most women did not know any form of treatment for UI or they had knowledge only about the surgery. This was the option most chosen among those who sought professional help [10], probably because it is type of treatment better known and more offered.

Educational interventions that promote reflection and bring clarifications on the PFD are necessary for the general population to be changes of knowledge. The generalist health professionals also need information about the impact of PFD on quality of life, its management and treatment. Especially those which are in primary care health services, thus leading, adequate assistance to those seeking help. 


\section{Conclusions}

In the present review, we noted that different behavioral and cognitive strategies were used in various studies. Educational technologies such as manuals, videos, pamphlets, reminders and educational programs were used. They have proved effective in expanding information and women treatment seeking. They showed great potential for reproducibility in other situations in order to improve the knowledge of these women, with PFD or with relevant risk factors.

We conclude that both behavioral strategies, cognitive and social, show positive effects in the treatment and prevention of UI. However, it is suggested that, where appropriate, they use a combination of interventions to obtain more effective result.

\section{Conflict of Interest Statement}

None declared.

\section{References}

[1] Haylen, B.T., de Ridder, D., Freeman, R.M., Swift, S.E., Berghmans, B., et al. (2010) An International Urogynecological Association (IUGA)/International Continence Society (ICS) Joint Report on the Terminology for Female Pelvic Floor Dysfunction. International Urogynecology Journal, 21, 5-26. http://dx.doi.org/10.1007/s00192-009-0976-9

[2] Lawrence, J.M., et al. (2008) Prevalence and Occurrence of Pelvic Floor Disorders in Community-Dwelling Women. Obstetrics \& Gynecology, 111, 678-685. http://dx.doi.org/10.1097/AOG.0b013e3181660c1b

[3] Coyne, K.S., Sexton, C.C., Thompson, C.L., et al. (2009) The Prevalence of Lower Urinary Tract Symptoms (LUTS) in the USA, the UK and Sweden: Results from the Epidemiology of LUTS (EpiLUTS) Study. BJU International, 104, 352-360. http://dx.doi.org/10.1111/j.1464-410X.2009.08427.x

[4] Flanagan, L., Roe, B., Jack, B., Barrett, J., Chung, A., Shaw, C. and Williams, K.S. (2012) Systematic Review of Care Intervention Studies for the Management of Incontinence and Promotion of Continence in Older People in Care Homes with Urinary Incontinence as the Primary Focus (1966-2010). Geriatrics \& Gerontology International, 12, 600-611. http://dx.doi.org/10.1111/j.1447-0594.2012.00875.x

[5] Mendes, K.D.S., Silveira, R.C.C.P. and Galvão, C.M. (2008) Integrative Literature Review: A Research Method to Incorporate Evidence in Health Care and Nursing. Texto \& Contexto Enfermagem, 17, 758-764.

[6] Melnyk, B.M. and Fineout-Overholt, E. (2005) Evidence-Based Practice in Nursing \& Healthcare: A Guide to Best Practice. Lippincott Williams \& Wilkins, Philadelphia.

[7] Vasconcelos, C.T.M., Damasceno, M.M.C., Lima, F.E.T. and Pinheiro, A.K.B. (2011) Integrative Review of the Nursing Interventions Used for the Early Detection of Cervical Uterine Cancer. Revista Latino-Americana De Enfermagem, 19, 8. http://dx.doi.org/10.1590/S0104-11692011000200028

[8] Palmer, M.H. (1995) A Health-Promotion Perspective of Urinary Continence. Nursing Outlook, 42, 163-169. http://dx.doi.org/10.1016/0029-6554(94)90004-3

[9] Ismail, S.I., Bain, C. and Hagen, S. (2010) Oestrogens for Treatment or Prevention of Pelvic Organ Prolapse in Postmenopausal Women (Review). Cochrane Database of Systematic Reviews, 8, 9.

[10] Ayeleke, R.O., Hay-Smith, E.J.C. and Omar, M.I. (2013) Pelvic Floor Muscle Training Added to Another Active Treatment versus the Same Active Treatment Alone for Urinary Incontinence in Women (Review). Cochrane Database of Systematic Reviews, 11, CD010551.

[11] Kim, J.I. (2001) Continence Efficacy Intervention Program for Community Residing Women with Stress Urinary Incontinence in Japan. Public Health Nursing, 18, 64-72. http://dx.doi.org/10.1046/j.1525-1446.2001.00064.X

[12] Tannenbaum, C., Agnew, R., Benedetti, A., et al. (2013) Effectiveness of Continence Promotion for Older Women via Community Organizations: A Cluster Randomized Trial. BMJ Open, 3, Article ID: e004135. http://dx.doi.org/10.1136/bmjopen-2013-004135

[13] Tak, E.C.P.M., Hespen, A., Dommelen, P. and Hopman-Rock, M. (2012) Does Improved Functional Performance Help to Reduce Urinary Incontinence in Institutionalized Older Women? A multicenter randomized clinical trial. BMC Geriatrics, 12, 51. http://dx.doi.org/10.1186/1471-2318-12-51

[14] Chiarelli, P. and Cockburn, J. (2012) Promoting Urinary Continence in Women after Delivery: Randomised Controlled Trial. BMJ, 324, 1241. http://dx.doi.org/10.1136/bmj.324.7348.1241

[15] Gorman, R. (1995) Expert System for Management of Urinary Incontinence in Women. Proc Annu Symp Comput Appl Med Care, 527, 31. 
[16] Lopes, M.H.B.M. and Higa, R. (2006) Urinary Incontinence Restrictions in Women's Life. Revista da Escola de Enfermagem da USP, 40, 34-41. http://dx.doi.org/10.1590/S0080-62342006000100005

[17] Simeonova, Z., Milsom, I., Kullendorf, A.M., Molander, U. and Bengstisson, C. (1999) The Prevalence of Urinary Incontinence and Its Influence on the Quality of Life in Women from an Urban Swedish Population. Acta Obstetricia et Gynecologica Scandinavica, 78, 546-551. http://dx.doi.org/10.1080/j.1600-0412.1999.780613.x

[18] Minassian, V.A., Drutz, H.P. and Al-Badr, A. (2003) Urinary Incontinence as a Worldwide Problem. International Journal of Gynecology \& Obstetrics, 82, 327-338. http://dx.doi.org/10.1016/S0020-7292(03)00220-0

[19] Hägglund, D., Walker-Engström, M.L., Larsson, G. and Leppert, J. (2001) Quality of Life and Seeking Help in Women with Urinary Incontinence. Acta Obstetricia et Gynecologica Scandinavica, 80, 1051-1055. 